\title{
Identity Manifestation in Second Language Writing through Notion of Voice: A Review of Literature
}

\author{
Shiva Javdan \\ University of Isfahan, Iran
}

\begin{abstract}
Voice, a discourse related notion, is a required criterion for writing acceptable English. However, L2 learners from cultures other than English might face problems in realizing it, or even ignore it all through their writing. In this connection, researchers seek to look at it through different angels. A well-known definition for it is given by Hyland (2008) as "the ways writers express their personal views, authoritativeness, and presence" (p.5). Also, researchers try to find the relationship between this notion and various aspects of writing like overall quality, identity manifestation and so on in order to improve the quality of writings produced by $L 2$ writings. This is supposed to assist $L 2$ writers to create more native like and smooth writings.
\end{abstract}

Index Terms - voice, identity, rhetorical features, discursive features

\section{INTRODUCTION}

Communication in writing is of great importance in today's world, despite the fact that it may take the forms of so called, traditional paper and pencil writing or electronic mail. Such importance calls for encouraging and nurturing writing as a communicative activity in second language learners' programs of language studies.

However, producing a communicative successful written text is a complex task which requires simultaneous control over a number of language factors in consideration of the ways the discourse must be shaped for a particular audience and a particular purpose (Olshtan, 2001).

Regarding language factors affecting a written text, Fox (1994) holds that language use is both culturally and socially determined. In other words, written texts are shaped by factors that differ not only cross- culturally, but also within a single culture.

Rhetorical styles are one of such differing factors. According to Stapleton (2002) the rhetorical styles of second language writers and the manifestation of them on the page is the topic of debates in second language writing.

The notion of voice is one of the language factors and rhetorical styles that Stapelton (2002) contends is an important part of writing and communicating, and aspects of it are essential at the higher levels of academic writing where authors are aiming to publish.

Among various definitions offered for voice, a well known definition for voice is given by Hyland (2008) as "the ways writers express their personal views, authoritativeness, and presence" (p.5). Authoritativeness and presence is of high importance in western cultures writing. Therefore, he believes that is not an optional extra but an aspect of how the writer positions himself in relation to his community. Importantly, Hyland argues that writers do not construct the selfrepresentation from an infinite range of possibilities, but draw on culturally available recourses when they write.

Regarding the constituents of this notion, Stapleton (2002) claims that they are resonance, sound, rhythm, liveliness and energy of the individual. He also considers voice as an integral part of writing and that it should, therefore, become an essential component of second language writing pedagogy. However, Jacobs in his voice intensity scale (1981), presents another four constituents for voice i.e., assertiveness, self-identification, reiteration of central point and authorial presence. Among other scales, his scale is widely used by researchers in order to measure the intensity of voice in research articles (Stapleton, 2002).

Concerning this notion, voice, Matsuda (2001) considers voice as a metaphor for capturing, among other things, or a feature in written discourse that can be percepted by readers, but is not readily recognizable as a single linguistic or rhetorical feature. So, it should be paid more attention while writing in English as a second language.

Also, in terms of modes of language that voice appears in, Bakhtin (1986) states that in addition to written discourse voice applies to spoken communication. He contends that voice is a broad issue that reveals the intention and perspective of a writer or speaker to the audience.

As a realization of voice in language, Elbow (1994) brings up the concept of "individualized voice" in writing that has caused considerable discussions about the role of voice in writing pedagogy. Elbow's definition for voice as a feature that "captures the sound of the individual on the page" was limited to the first language for English speakers. This has recently been debated extensively in L2 writing circles, as well. Matsuda (2001) states that much of these debates aroused due to the performance of learners who are from interdependent cultures. He explains that these 
cultures have collective values that overweigh the individualism in their writing. Such learners present their L1 values and social norms while writing in English, as well. As a result of this lack of identity and individualism their writing might be judged as substandard.

With this regard, Kaplan (1987) argues that interdependent or hierarchical norms might halt L2 learners from presenting a strong voice in their writing or diminish their presence as authors. In connection with this view and concerning language pedagogy, Matsuda (2001) claims that then L2 learners need to be taught or at least made familiar with certain features that enhance a writer's voice.

However, some factors hinder L2 learners from manifestation of voice while writing. In this regard, Belcher (1997) in a study sought to identify voice- related issues and dilemmas, and how they were resolved. In describing a participant, a $\mathrm{PhD}$ candidate, whose papers were published in Spanish medium and had a degree from an American university, yet he was in the middle level of his ESL writing class. According to him, this participant seeks a voice as an identity maker that that would begin to approximate the one he was moving from. Belcher argues that he wanted something beyond the technical aspects of writing; that should be voice.

The idea of whether voice should be considered by writing teachers has been long debated. For example, in a study, Ivanic (2001) suggests that L2 learners are in need of a critical awareness for voice to project their own self in their writing. Such idea, critical awareness- rising, enables learners to find the consequences of their identity and voice type they apply. He argues that for L2 writers might have a double demand for such awareness in order to: firstly, recognize how much the target voice is culturally alien to their L1 culture, and secondly, recognize the type of voice appears in range of genre in the new culture.

Also, the function of first person has aroused debates in the notion of voice in qualitative studies. Hyland (2008) considers the first person usage as an important element in projecting the identity of authors. Tang and John (1994) classified notion of voice into six identities based on its application in a sentence.

Representative - " in English we have words such as ..."; guide - "so far, we have said nothing about ..."; architect - "in my essay, I will examine ..."; recounter of the research process - "all the papers I read were ..."; opinion holder -"I would like to show that ..."; and originator - "my idea rests on the assumption that ..." (p.36-37).

In order to classify they took academic writing samples from different available choices. They noticed that if L2 writers be aware of different available choices they have, they may decide better to how best project their individualism on the paper, while some L2 learners might avoid presenting first person in their writing since they have been taught to take an impersonal stance in academic writing.

Finally in terms of voice construction among languages, Matsuda (2001) contends that the ways in which voice is constructed, however are not universal; different languages provide different possibilities for construction of voice. He argues that the difficulties that the Japanese students encounter in constructing voice in English discourse are due to the ways in which voice is constructed in their native culture and English.

Regarding the aforesaid rhetorical features and lack of awareness of such cross-cultural differences in the text structure that cause misunderstanding in the languages of different societies, as well as the ignorance of L2 learners from the available choices to construct their voice, and the fact that it might become a hinder to effective intentional communication of authors' intentions, this study seeks to review different aspects of the notion of voice.

\section{STATEMENT OF PROBLEM}

Fox (1994) in a study found that L2 writers do not project appropriate authorial presence while this is deemed as an important quality in English writing. She focuses on the shortcomings of analytical writing of second language writers. According to her, English writing should be along with authorial voice. She highlights that most cultures do not expect such an apparent voice in written context; however, it is required in the U.S. She states that the problem that exists for most L2 writers' writing is the lack of such authorial voice.

Moreover, in his study, Shen(1998) discusses that voice is mostly a cross-culturally different notion. He adds that learning writing in English requires learners to project an individual identity, or infocus their writing with voice. According to him there are some features in his own culture, Chinese, that contrasts with English writing, for example English writing is straightforward while Chinese is not, and that causes problems for Chinese English learners' writing.

As reported by Ivanic and Camps (1997), in using their participant of passive voice, the student author implies the responsibility of unnamed agent for the exploitation. They explain that second language learners have perceived that they should apply passive voice in their writing to be left unknown while writing in order to give more weight to the content through use of this grammatical technique. In their study, they take well-established concepts from conventional forms of pedagogy, i.e., vocabulary and grammar acquisition and associating them with a newer and perhaps trendier notion, voice, which has been neglected by both teachers and learners.

However, Matsuda (2001) believes that the issue of finding socially and discursively constructed identity is not unique to non-native speakers or students from other counties; rather it can be problematic to students who were brought up in the United States. Similarly, Ramanathan and Kaplan (1987) argued that projecting voice in written discourse is not just the problem of L2 learners. Rather, mainstream students have difficulties in this regard. This is evident through the numerous comments regarding voice projection that teachers put in their writing. They believe that although both mainstream students and those who have just arrived from outside show problems related to voice and 
identity projection for the first group it is less troublesome since they and their audience have the same social and cultural practices, while this is not the case for the second group.

\section{ISSUE OF VOICE}

The way one puts his ideas on the page is extremely affected by his first language and culture. However, there are still disagreements about the extent to which teachers need to consider this knowledge. Therefore, the debates are on the issue of voice and its associated discursive features are so vigorous (Stapletan, 2002).

Voice is a metaphorical concept owes much to the thinking of Bakhtin and his work in the field of linguistics (Stapleton, 2002). Bakhtin (1986) believes that voice is not just applied to spoken but to written discourse as well. He adds that voice presents views and intentions of an author. He argues that through using voice the writer or the speaker chooses how to respond the previous utterances. Some utterances he explains reflect a multiple voice which stems from a borrowed language they contain plus the voice of the individual.

Various definitions has been given for voice, for example, Stewart (1972) calls authorial voice the quality that distinguishes each human from another, whereas Elbow (1994) describes it as writing that "captures the sound of the individual on the page" (p.287).

Matsuda (2001) tries to look at voice differently. Borrowing from Ivanic (1997) he States that: "Voice is the allmalgative effect of the use of discursive and non- discursive features that language users choose, deliberately or otherwise, from socially available, yet ever changing repertoires"(p. 40).

Atkinson considers this as a clear definition; however, he maintains that voice remains "a devilishly difficult concept to define" (p.110). With this respect, Stapleton (2001) believes that this may be due to the ineffable qualities attributed to voice that makes it difficult to define. Elbow (1999) on the other hand, argues that voice is a dimension of the text that is rhetorically powerful but hard to focus on. He believes that there are some covert and implied messages in the texts for the audience that is carried through the notion of voice not just words.

\section{Voice IN SeCond LANGUAGe Writing}

Arising the notion of voice in research revealed that social values, culture and practices of L2 writers plays a halting role against taking an individual and authorial voice and consequently identity projection by L2 writers of English . With this respect, Connor and Kaplan (1987) stated that learners from interdependent cultures whose values are hierarchical may avoid projecting a proper authorial voice or diminish their presence as authors as well.

In alignment with the above view, Shen (1998) in describing the difficulty of writing in English involves a process of creating a new identity. $\mathrm{Li}$ (1996) also, echoed the notion of individual identity in his study. He searched the ideas of Chinese and American instructors to find the determining factors of good English writing. His survey revealed that American instructors marked good English writing by a writer's unique perspective of life; however, for Chinese instructors such concept was alien.

Matsuda (2001) in his study claims that $\mathrm{L}_{2}$ Learner need to be taught or at least made cognizant of certain features that enhance a writer's voice. He identified aspects of authorial identity and authorial presence which can be used and measured in studies in order to determine how native speakers and L2 learners project them while writing in English.

Stapleton's findings (2002) are in line with that of Li (1996). He highlights that projecting individual voice is required for an acceptable English writing. He clarifies that writings that lack a proper authorial voice and identity might sound substandard to the native audience. According to him, participants in his study and the previous studies on voice made conscious choices about how to present their identity on the page.

\section{VOICE STUDIES}

Stapleton (2002) classifies studies focusing on voice in to two classes: i.e., autobiographic and semi-ethnographic studies or linguistic studies.

\section{A. Autobiographic and Semi-ethnographic Studies}

Shen (1998) conducted an autobiographical study in which the main concern was the voice that an L2 writer applies while writing English compositions. He explains that in order to write an acceptable composition in English he had to make a new English self out of herself. Actually, he had to violate his Chinese propensity in writing while using first person singular in English, i.e., against tending to modesty in his L1 culture.

He claims that English writing is straightforward and that acceptable English writing first concern is the audience , and if it is hostile, will take an "Unfolding approach", as opposed to a "self- announcing" deductive one. He asserts that they do it not to alienate the reader at the outset to ideas that may be adversial.

Cadman (1997) and Fox (1994) in their semi-ethnographic studies discuss examples that did not include the qualities of authorial presence that are deemed to be of high importance in English.

Cadman (1997) brings an example, a PhD student, whose writing lacked the authorial presence qualities. Cadman states that a culture gap caused such problem. However, the student gradually put her voice in writing when she 
receives some instructions in this regard. Cadman also describes another participant's work in alignment with Shen's study.

In another study, Atkinson (1999) highlights that in order to write in English effectively learners have to present an individualized voice or identity. It should be noted that such self-representation would be alien in some $\mathrm{L}_{2}$ cultures. He describes that how a postgraduate student was confused and frightened due to the lack of schemata for many of the essential elements in western scholarship.

Finally, Fox (1994) has comments about expectations of an L1 audience .He contends that English rhetoric is linear and deductive, and ignores unfolding structures, while many other languages are circular or non-linear.

\section{B. Linguistic Studies}

Some researches focused on linguistic features pertaining to author's identity and presence which gives a concrete pedagogical sense to the notion of voice (Stapleton, 2002). In this connection, Ivanic and Camps (2001), picked six graduate students to examine the way they represent themselves in their writing. According to them, learning to project a positioning power in written discourse is vital for L2 writers. They add that this skill should be learned at the beginning of a writing course. Also, they studied the lexical, syntactic, and rhetorical choices made by their participants to construct their identity. Based on their report, the type of voice the participants chose positioned them as "sounding like" members of certain social group. As for an example of positioning power, Ivanic and Camps report that it can be displayed via one's distinctive lexical choices. They found the lexical items apply by one of their participants totally different from the others who were studying in different areas.

As a linguistic notion, the use of the first person is perhaps the most discussed discursive features associated with voice. Stapleton (2002) believes that in both qualitative and quantitative studies, the first person it is the key element in establishing individual identity. Also, Hyland (2001) in a study focused on the use of first person pronouns and selfcitations. His findings indicated that self mentioning among different disciplines has a broad range for example, in the humanities and social sciences entails many more usages of first person, than those in science of engineering.

\section{SignificANCE OF RESEARCH IN VoICE}

Voice is one of the features of writing skill which may contribute to the quality of students' writing. Matsuda (2001) asserts that voice is a valuable tool for writer of all culture and problems that L2 writers face might stem more often form ignorance of appropriate voice-related strategies in English writing. As he believes, the notion of voice together with all other concepts in writing answers the expectations of the reader and the lack of one makes the writing substandard in one way or another.

Matsuda (2001) also asserts that some discursive features are unique in languages. For example, in Japanese some qualities like multiple orthographic systems, sentence final particles, as well as variations in personal pronouns cannot be found in English. He concludes that features which are not cross- cultural need to be noticed to L2 learners in order to produce more native-like writings, otherwise they might get stranded on how to present these features while writing in L2, or even they may ignore it all through the way.

With this respect, some discursive qualities are related to voice construction have a nature of language- specific. They have great implications in L2 writing pedagogy, as well as research. Also, there are some qualities that have no counter parts in English. Atkinson (1999) assumes that since these features might not be positively transferred to facilitate the discursive construction of voice in English, they are of high importance in teaching writing to L2 learners.

However, regarding the statements of Hinkle (2002), there is a fundamental problem in conducting research in voicerelated issues and the use of native speakers' corpora. Actually, the major lack is the access to the type of linguistic and rhetorical devices the native speakers choose to enrich their discourse. In this connection, some experimental studies are required to identify the relationship between the use of these devices and the overall quality, if it exists whatsoever.

Importantly, Stapleton (2002) considers the notion of voice as a critical aspect of writing discourse that should be brought in the realm of pedagogy either through consciousness raising or other ways. He believes that the writing procedure by native speakers or non-natives are firstly viewed in terms of originality and quality of ideas that the writer presents them via employing different discursive features like the notion of voice. Considering the aforesaid, the results of this study can assist language instructors to focus on the features of this critical component of language to guide the learners in the right path of academic writing skill. The targeted text type in this study; persuasive, is known as one of the most common ones in academic writing. As Ferris (1994) states that persuasive writing is an important and difficult mode of discourse for student writers especially for non-native speakers who often bring linguistics and rhetorical deficits to the task of persuasion in English.

Considering the above said implications of voice in L2 learning and pedagogy, this notion has a vast vacancy to work on to clarify its blur points.

\section{SUMMARY}

In addition to lexical and syntactical factors contributing a decent and acceptable piece of writing in English other aspects like rhetorical styles make a difference. As a major rhetorical style, voice does not have the same manifestation 
across cultures. Therefore, L2 writers incognizant of this difference use their L1 voice in their L2 productions, so they do not meet the requirements of presenting a self-identity quality in English writing while such quality in writing deems as a must by native speakers. As a result, their writing sound unnatural since something i.e., target voice delicately is missing there. This evokes researchers to conduct vast studies regarding this notion in order to assist L2 writers to overcome such drawback in their L2 written productions. Also, material designers need to enrich writing pedagogy courses via incorporating voice properly into writing syllabi. Therefore, this notion deserves special care and attention on the part of writing teachers, material designers as well as L2 learners.

\section{REFERENCES}

[1] Atkinson, D. (1999). TESOL and culture. TESOL Quarterly, 33 (4), 625- 654.

[2] Bakhtin, M. M. (1986). From speech genres and other late essays. In P. Morris (Ed.), The Bakhtin reader (pp. 81-87). New York, NY: Oxford University Press.

[3] Belcher, D. (1997). An argument of non-adversial argumentation: The feminist critique of academic discourse to L2 writing pedagogy. Journal of Second Language Writing, 6, 21.

[4] Cadman, K. (1997). Thesis writing for international students: A question of identity? English for specific purposes, $16,3-14$.

[5] Connor ,U., \& Kaplan ,R. (1987). Writing across languages: Analysis of L2 text. USA: Addison - Wesley.

[6] Elbow, P. (1994). Landmark essays on voice and writing. Davis, CA: Hermagoras Press.

[7] Fox, H. (1994). Listening to the world: Cultural issues in academic writing. Urbara Illinois: National Council of Teachers of English.

[8] Hyland, K. (2008). Disciplinary voices: Interactions in research writing. English Text Construction, 1 (1), 5-22.

[9] Ivanič, R. (1997). Writing and identity: The discoursal construction of identity in academic writing. Amsterdam: John Benjamins.

[10] Ivanič, R., \& Camps, D. (2001). I am how I sound: Voice as self-representation in L2 writing. Journal of Second Language Writing, 10(1-2), 3-33.

[11] Jacobs, H. L., Zinkgraf, S. A., Wormuth, D. R, Hartfiel, V. F., Hughey, J. B (1981). Testing ESL composition: A practicalapproach. Rowly, MA: Newbury House.

[12] Kaplan, R. (1987). Cultural thought patterns. Writing across languages. Analysis of L2 tests (pp.9- 21). Addison Wesley.

[13] Li, X. (1996). Good writing in cross cultural context. Albary: State University of New York Press.

[14] Matsuda, P.K. (2001). Voice in Japanese writers discourse: Implications for second language writing. Journal of Second language writing, 10, 35- 53.

[15] Olshtan, E. (2001). Teaching English as a second or foreign language: In B. Kroll, Exploring the Dynamics of Second Language Writing: Cambridge University Press.

[16] Shen, F. (1989). The classroom and the wider cultare: Identity as a key to learning English composition. College Composition and Communication, 40 (4), 469- 466.

[17] Stapleton, P. (2002). Critiquing voice as a viable pedagogical tool in writing: Returning the spotlight to ideas. Journal of Second Language Writing 11, 177-190.

[18] Stewart, D.C. (1972). The authentic voice: A pre- Writing approach to student writing. Dubuque, IA: W.C.Brown.

[19] Tang, R., \& John, S. (1999). The "I" identity: Exploring writer identity in student academic writing through the first person pronoun. English for Specific Purposes, 18, 23-39.

Shiva Javdan is an MA Student in TEFL at the University of Isfahan, Iran. Her research interests include intercultural communications, CDA and second language writing. 